\title{
Investigación científica y patentes: análisis ético-jurídico de sus relaciones
}

Salvador Darío Bergel

\section{Resumen}

La investigación científica y el derecho de patentes pertenecen a dos mundos muy diferentes, lo que no imposibilitó que existan puntos de contacto. Mientras se observaron los principios liminares que autorizan el otorgamiento de una patente (existencia de una invención patentable, novedosa, con altura inventiva y aplicación industrial) no se vislumbraron conflictos. Los cambios operados en el derecho de patentes como fruto de una creciente presión de los mercados ha llevado a una transformación que perturba la libre circulación del conocimiento y la investigación científica en sí; temas de indudable interés ético. En este trabajo se describen las notas más significativas de este proceso, así como los conflictos más relevantes que se suscitaron.

Palabras-clave: Patentes como asunto-Ética. Propiedad-Invenciones-Conocimiento. Investigación-Propiedad intelectual. Leyes-Marcas registradas.

\section{Resumo}

Investigação científica e patentes: análise ético-jurídica de suas relações

A pesquisa científica e o direito de patentes pertencem a dois mundos muito diferentes, o que não impossibilitou que existam pontos de contato. Embora se tenha observado os princípios basilares que autorizam a concessão de uma patente (existência de invenção patenteável, inovadora, com cunho inventivo e aplicação industrial) não não se vislumbraram conflitos. As mudanças feitas no direito de patentes como fruto da crescente pressão do mercado, levou a uma transformação que perturba a livre circulação do conhecimento e da pesquisa científica em si; temas de indiscutivel interesse ético. Neste trabalho se descrevem os aspectos mais significativos deste processo, assim como os conflitos mais relevantes que foram suscitados.

Palavras-chave: Patentes como assunto-Ética. Propriedade-Invenções-Conhecimento. Pesquisa-Propriedade intelectual. Leis-Marcas registradas.

\section{Abstract}

\section{Scientific research and patent law: ethical and juridical relationship between them}

Scientific research and patent law belong to two very different worlds, which made dificult that there are points of contact. While the underlying principles that authorize the granting of a patent (existence of a patentable invention, novelty, a inventive improve in the object or capacity in question and there industrial application) envisioned no conflicts were observed. The changes in patent law as a result of increasing market pressure has led to a transformation that disturbs the free movement of knowledge and scientific research itself; ethical issues of undoubted interest. The most significant notes of this process are described in this work as well as the most important conflicts that arose.

Keywords: Patents as topic-Ethics. Ownership-Inventions-Knowledge. Research-Intellectual property. LawsRegistered trademarks.

Doutor s.bergel@zbv.com.ar - Cátedra Unesco de Bioética en la Universidad de Buenos Aires, Buenos Aires/CF, Argentina.

\section{Correspondência}

Florida 537 Piso $18^{\circ} \mathrm{C} 1005 \mathrm{AAK}$. Cidade Autônoma de Buenos Aires/CF, Argentina

Declara não haver conflito de interesse. 
Tradicionalmente se consideró que el derecho de la propiedad industrial se movía en un mundo eminentemente técnico para regular los derechos atribuidos a quienes incorporaban a la sociedad innovaciones mecánicas, traducidas en aparatos, instrumentos, equipos, instalaciones, etc. En un momento posterior apareció la industria químico-farmacéutica. Muy lejos estaban los seres vivos, la materia viva, el material genético, que pertenecían a otro mundo.

Cuando surgió la biotecnología moderna y se pudo apreciar el valor de mercado de los productos y procesos biotecnológicos se suscitó el debate sobre la incorporación de seres vivos, sus partes, el material de reproducción, al derecho de la propiedad industrial. Con diversos argumentos - ensayados para las nuevas realidades - las oficinas de patentes, los tribunales de justicia y las leyes fueron incorporando insensiblemente a microorganismos, plantas, animales, material biológico y genético humano, todo lo cual llevó a considerar una cierta relación entre la propiedad industrial y los principios éticos.

Una muestra cabal de ello y de la rapidez con que operó este cambio es el proceso de elaboración de la Directiva Europea sobre Protección de las Innovaciones Biotecnológicas (98/44C) ${ }^{1}$. En poco más de dos lustros que tardó en ser sancionada, se pasó de un texto que no contenía ninguna mención ética a la Directiva finalmente aprobada que dedicó cerca de la mitad de su contenido a los temas éticos que planteaban la admisión de la materia y los seres vivos al mundo de la propiedad industrial.

De todas formas se insistió en no modificar sustancialmente los principios centrales de la disciplina. La patente se puede otorgar a las invenciones que observen los requisitos objetivos de patentabilidad (ser nuevas, tener una cierta altura inventiva y una aplicación o utilidad industrial).

La observancia de este esquema contribuyó a balancear el sistema: el titular de la patente se beneficia con la explotación del invento (producción, comercialización, explotación, etc.) y paralelamente la sociedad se beneficia al incorporar a su acervo un conocimiento más, que eventualmente podrá servir de base a otros hallazgos en el futuro.

Mientras se mantuvo la línea divisoria entre invento (patentable) y descubrimiento (no patentable) el funcionamiento del sistema permitió un cierto grado de equilibrio entre intereses que parecieran ser contrapuestos en razón de la diversidad de fines perseguidos.

Ahora nos enfrentamos a un cuadro que desafía ese equilibrio. Muy especialmente a partir del desarro- llo exponencial de la biotecnología y ciencias conexas, la línea divisoria entre invento y descubrimiento pareciera haberse esfumado. La legislación sobre patentes, así como la jurisprudencia - anota Pestre - fueron aquí decisivas, extendieron ampliamente el campo de aplicación de la patentabilidad y constituyeron el medio privilegiado por el que el universo mercantil llevó a cambiar los equilibrios anteriores y hacer prevalecer la norma de la mercantilización como única eficaz ${ }^{2}$.

Esta nueva situación replantea los objetivos de la propiedad industrial: vector de la difusión del conocimiento en beneficio de la sociedad o traba a su libre circulación.

En el presente trabajo nos proponemos analizar desde la órbita de la investigación científica la nueva función de la propiedad industrial, análisis que naturalmente envuelve aspectos éticos y jurídicos de gran trascendencia social.

Protección de la investigación científica en la legislación de patentes

Habida cuenta que el derecho de exclusiva del que goza el beneficiario de la patente puede llegar a interferir a la investigación científica, las leyes de patentes utilizan tres antídotos para salvarla, a saber:

a) La exclusión de los descubrimientos, en tanto que el descubrimiento pertenece al mundo de la observación y no al de la creación;

b) La excepción de experimentación que autoriza en ciertos casos la utilización del producto o del procedimiento patentado para fines experimentales, sin ser sancionado quien lo utiliza;

c) La existencia de un período de gracia para patentar, lo que permite divulgar el producto o el procedimiento a ser patentado durante un tiempo limitado anterior a la solicitud, sin perder la posibilidad de patentar.

De estos tres antídotos, sin duda, el primero es el más importante y está receptado en la generalidad de las legislaciones. El segundo ofrece dudas sobre si la excepción permite la experimentación basada en una invención o con una invención. El tercero, a su turno, es aceptado en algunos países y en otros no (v. gr. los europeos).

\section{Cambios operados en el derecho de patentes}

Es evidente y no necesita de mayor desarrollo que el derecho de propiedad industrial en el que se 
asienta el mundo de las patentes ha sufrido cambios que amenazan con destruir sus bases de sustentación. Correa citando Dickson afirma que estos cambios no sucedieron por casualidad sino que tienen su fundamento en la forma en que se desarrolla la investigación científica en lo que se ha llamado la economía de la innovación ${ }^{3}$.

La financiación pasó a convertirse en un factor decisivo y el inversor en actor importante en el aprovechamiento de los resultados de la investigación. En este proceso - se ha señalado - el saber más abstracto se vuelve un factor financieramente visible y directo de la producción ${ }^{4}$. Los planes de investigación apuntan en este nuevo contexto a la marginación de las preocupaciones a largo término, con una reducción de las investigaciones heterodoxas y "gratuitas", una focalización y una concentración sobre los dominios "monetizables".

Las universidades se han vuelto actores directos del desarrollo industrial y cada vez más abandonan su naturaleza de proveedores de "ciencia abierta" participando en el registro de patentes, así como en los acuerdos de licencias ${ }^{5}$. De común la unión de las universidades públicas con las empresas privadas apunta a satisfacer en mayor medida los intereses y las necesidades de éstas, tales como: una pronta ganancia sobre la investigación, atraparla en las primeras fases para evitar la competencia, bloquear las investigaciones futuras cubriendo con patentes todo el espectro relacionado con la investigación de la que se trate, utilizar las patentes como arma anticompetitiva.

La necesidad de responder a estos fines acrecienta la lucha por la posesión de patentes, sin que interesen mayormente sus contenidos o su contribución al progreso de las ciencias y de las técnicas. En el nivel global el resultado de esas batallas por una apropiación mayor de los resultados de la ciencia fue un acrecentamiento de las prácticas de secreto y una tendencia a la constitución de monopolios nuevos sobre ciertos productos e investigaciones.

\section{Efectos sobre la investigación científica de los cambios en el derecho de patentes}

Los cambios operados en el derecho de patentes se han traducido en un conjunto de prácticas que a la postre afectan a la investigación científica. Pasamos a referirnos a ellas.
La patentabilidad en las primeras etapas de la investigación

La prevalencia de la competencia económica por sobre los aspectos técnicos de las invenciones llevó a acelerar los tiempos y a solicitar patentes aun cuando la supuesta invención se encontrara en las etapas iniciales, lo que naturalmente no permite su utilización concreta.

Una invención - vale la pena reiterarlo una vez más - implica la culminación de un proceso creativo dirigido a satisfacer un problema técnico de interés humano. En Corea y en Japón el término "invención" hace referencia a una creación sumamente avanzada de ideas técnicas en las que se utilizan las leyes de la naturaleza. En ambos casos se entiende que esta definición excluye la patentabilidad de las leyes de la naturaleza, los meros descubrimientos, las ideas que no son técnicas, las soluciones a problemas que sean imposibles de resolver, las innovaciones que no se basen en las leyes de la naturaleza y las innovaciones que sean contrarias a esas leyes ${ }^{6}$. Hago hincapié en la expresión "muy avanzada", lo que implica la culminación de un proceso creativo que, de común, es concebido en etapas.

Sobre todo las investigaciones en el campo de la biología importan un considerable esfuerzo que puede o no llevar a la verificación de una hipótesis, o que llegado a buen fin no se traduce necesariamente en una invención patentable por no darse los extremos requeridos por la ley para que ello acontezca, quedando en todo caso como un aporte de ciencia básica. Hoy, la prevalencia de la economía de la innovación exige en forma continua nuevas patentes sin que la investigación llegue a un resultado útil o práctico. Este es un fenómeno que ha sido debidamente estudiado en el campo de la biología.

Gran parte de los conocimientos producidos en el área de las biotecnologías - enseñan Dal Paz y Denis Barbosa - tienen potencial técnico, mas no inmediato y directo. Estratégicamente existe un interés de los agentes económicos (no necesariamente un interés público) de anticipar la apropiación de tecnología. Por esto se ven tentados de patentar procesos biotecnológicos, biomoleculares, de modo combinado con las secuencias de ADN que le están relacionados ${ }^{7}$.

En un número significativo de casos las prácticas relativas a biotecnología son actividades de ciencia, tecnología e innovación en progreso y de larga maduración. La patentabilidad temprana cuando sólo se han dado los primeros pasos del proce- 
so de investigación sólo puede satisfacer criterios empresariales de reserva estratégica de mercado o de creación de pool de patentes con finalidades puramente mercantiles, lo cual resulta muy negativo para la investigación científica en general.

Cuando se patenta en los primeros estadios de la investigación en realidad no se está patentando una creación técnica que solucione un problema técnico, sino que simplemente se están patentando conocimientos - técnicos o científicos - que libremente transmitidos y utilizados sin los impedimentos que genera la patente podrían resultar útiles para intentar o proseguir otras investigaciones, que al ver bloqueado su camino no son emprendidas por otros investigadores para no enredarse en litigios judiciales.

La necesidad de disponer libremente de las "herramientas de investigación" es referida por Axel Kahn, destacado científico francés, en estos términos: un principio esencial en esta materia es el de crear las condiciones que tornen posible la invención. Esto pasa por la preservación del ideal científico y de las condiciones necesarias para su realización, permitiendo la acumulación de los conocimientos y de las herramientas de investigación, las que deben permanecer libremente accesibles para que los investigadores las utilicen en nuevas invenciones útiles. Tiende a evitar que haya un monopolio temprano del conocimiento demasiado aguas arriba de ese continuum que va del conocimiento a la invención. Estos conocimientos así acumulados son necesarios para que florezca la actividad inventiva ${ }^{8}$.

Las investigaciones se emprenden en función de hipótesis que son verificables con diversos resultados. Es ajeno al mundo de la ciencia el conflicto y en razón de ello los investigadores prefieren no recurrir a la utilización de conocimientos ya bloqueados por patentes. Resulta muy ilustrativo sobre este particular lo sucedido con la investigación genómica.

La patentabilidad en las primeras etapas de desarrollo de una investigación encontró en las oficinas de patentes suficiente apoyo para bloquear futuros desarrollos por otros investigadores, al otorgar al primero que patenta derechos que claramente exorbitan el aporte realizado. A ello hay que agregar que casi todas las doctrinas actuales muestran un sesgo hacia el "innovador" inicial 9 .

En esta línea, la Cámara de Recursos de la Oficina Europea de Patentes (OEP) considera que el "inventor" no puede ser sancionado y penalizado en razón de lagunas de las ciencias en el dominio que le concierne y que por tanto la extensión de la protección acordada por la patente no debería ser reducida a lo que efectivamente consiguió ${ }^{10}$. En el supuesto de patentes fundadas sobre un elemento del conocimiento en un dominio aun imperfectamente conocido la protección a juicio de las oficinas debe englobar las hipótesis que el depositante no habría visualizado en su solicitud ${ }^{11}$.

La posición de las oficinas sobre este particular resulta inexplicable. La Cámara de Recursos Técnicos de la OEP entiende que si la reivindicación se fundara sobre lo que efectivamente se describe, el patentado no dispondrá de una protección eficaz. La extensión de la protección conferida por la patente, extendida a toda la potencialidad del gen, posibilita bloquear la investigación biomédica subsiguiente ${ }^{12}$. Decimos que resulta inexplicable por cuanto en el supuesto que se admita la patentabilidad de genes más allá de los límites de lo efectivamente descripto por el solicitante, ello importaría al mismo tiempo admitir la protección de una investigación incompleta, tal como si el principio general fuere el de la protección vía patente y la excepción el de la libre circulación del conocimiento.

Resulta muy ilustrativo el análisis de las políticas de patentabilidad generadas en el campo de la genómica, campo que es y será en los próximos años muy requerido por los investigadores en tanto que secuenciado el genoma humano se han abierto vías conexas que pueden conducir a logros significativos en cuanto a la etiología y cura de múltiples enfermedades. Paralelamente a los primeros pasos de la secuenciación se desató una verdadera competencia entre empresas farmacéuticas o constituidas a ese solo efecto para apropiarse de la información genética a medida que era develada. No sólo se patentaron genes sino secuencias parciales, promotores, SNP's, etc. En muy poco tiempo una parte considerable del genoma humano estaba protegido por patentes. El número de las patentes concedidas fue realmente impresionante, ya que se las podía contar por miles ${ }^{13}$.

La postura de los investigadores desde los inicios fue contraria a la patentabilidad. En la reunión de Bermuda en febrero de 1996 los científicos pretendieron ponerse a cubierto del acecho de los sectores mercantiles. Allí acordaron dos principios: 1) compartir los resultados de la secuenciación "tan pronto como fuera posible" difundiendo los tramos de ADN superiores a mil pares de bases y; 2) 
prometieron suministrar estos datos dentro de las 24 horas de obtenidos a la base de datos públicos "Gen-Bank". El objetivo del acuerdo fue prevenir que los centros de investigación establecieran una posición privilegiada en la explotación y control sobre las secuencias humanas ${ }^{14}$.

Con el número y variedad de patentes concedidas sobre el genoma humano se construyó una verdadera maraña de patentes, que si bien sirvió para contribuir a monopolizar el mercado por parte de las empresas que concibieron ganancias extraordinarias, desde el punto de vista de la investigación científica fue y sigue siendo sumamente negativo. Ya en 1998 Heller y Eisenberg advirtieron acerca de la existencia de los inconvenientes de un exceso de derechos privados acumulados y superpuestos sobre genes y secuencias. A su juicio esta multiplicación de propietarios sobre la investigación genómica tornaba difícil el ensamblaje de los derechos de propiedad necesarios para el desarrollo de una innovación ${ }^{15}$.

Un tema conflictivo es el relativo a la necesidad de utilizar diversas "invenciones" cubiertas por patentes en una misma investigación. En genómica las investigaciones efectuadas por diferentes laboratorios no son independientes entre sí. La utilización del material genético patentado por uno de ellos ( $v$. gr. receptores o marcadores genéticos) puede ser necesario para proseguir investigaciones realizados por otros. En materia de vacunas es altamente improbable que una sola empresa pueda ser titular de cada uno de los componentes de la vacuna. A fin de evitar ulteriores procedimientos judiciales se torna necesario obtener licencias, lo que naturalmente entorpece el curso de la investigación. El titular de las patentes sobre una "herramienta de investigación" eventualmente reivindica su derecho a la invención últimamente realizada por medio de ese instrumento ${ }^{16}$.

En la práctica la necesidad para una empresa o laboratorio universitario de utilizar instrumentos de investigación patentados los conducirá a negociar licencias contractuales con los titulares de dichas patentes. En tal caso la posibilidad de proseguir la investigación dependerá de las condiciones en que se acuerde la concesión de la licencia ${ }^{17}$. En 1997 ya se habían presentado conflictos entre empresas genómicas, lo que hacía presagiar futuras contiendas entre quienes secuenciaban el gen y quienes lo relacionaban con una enfermedad o función biológica. Así el suscitado entre Millenium y Hoffman Laroche, por un lado; y Progenitor por otro, en relación con el gen receptor del leptin ${ }^{18}$.

En un estudio producido por el Nuffield Council on Bioethics se señala la forma por medio de la cual la patentabilidad de secuencias de ADN que sólo obtienen una utilidad primaria como herramientas de investigación afecta a ésta:

- el costo de investigación puede incrementarse, ya que el aumento de patentes otorgadas importará que se requieran más licencias en el desarrollo de futuras investigaciones;

- la investigación se vería dificultada si a los investigadores se los obligara a negociar primero el uso de genes y secuencias patentadas;

- un titular de patentes retendría el derecho de licencia para obtener el máximo de beneficios iniciales o, en su caso, la licenciaría en exclusividad a uno o a un número limitado de licenciatarios;

- las empresas que deseen adquirir los derechos de varias secuencias de ADN decidirán no desarrollar proteínas terapéuticas o test diagnósticos a consecuencia del costo de las regalías requeridas.

En base a estas consideraciones el Consejo estimó que el ejercicio de un monopolio sobre descubrimientos esenciales de información genética accesibles por métodos de rutina, era altamente indeseable ${ }^{19}$. En materia vegetal es tal la gama de reivindicaciones que se pueden presentar en relación con un único componente o carácter, que son frecuentes los casos en que una misma planta es objeto de múltiples patentes. En el caso de las plantas transgénicas y los productos de agrobiotecnología, todos y cada uno de los componentes y de los procesos pueden estar protegidos por derecho de propiedad intelectual ${ }^{20}$.

La investigación bajo secreto y la restricción a las comunicaciones científicas

Si el conocimiento, aun el más abstracto, se transforma en una mercancía al poder ser patentado, la investigación científica termina por adaptarse a ello y comprometer sus fines. Divulgar los diferentes pasos de una investigación puede resultar perjudicial a quienes la están financiando y esperan obtener réditos inmediatos de su apropiación, aún en una etapa inconclusa. De allí que se hayan impuesto en forma cada vez más acentuada prácticas ajenas al ethos de la ciencia. Esto opera tanto a nivel empresarial como a nivel de las universidades que se han vinculado con el mundo mercantil para lograr réditos en las investigaciones programadas.

En las universidades francesas la práctica de tesis "bajo embargo" es cada vez más frecuente. Tales prácticas parecen eminentemente secretas y celosamente controladas. Al tiempo que descono- 
cen la tradición científica de comunicación abierta entre colegas y de publicaciones en revistas científicas, congresos, etc., resultan decisivamente perjudiciales para la investigación, la que se nutre de intercambios de conocimientos y de experiencias ${ }^{21}$.

La intensificación de relaciones entre la investigación pública y las empresas, y la multiplicación de contratos de investigación que ello supone importó la generalización de la obligación de secreto impuesta por las empresas que financian el trabajo. La extensión de los principios del mercado llevó a los laboratorios públicos de investigación a una estrategia de retención de informaciones como asimismo de disminución de publicaciones de carácter académico. Hoy una parte importante de la investigación básica conduce en forma directa a la patentabilidad sin conocerse a ciencia cierta la aplicación práctica, presupuesto de toda protección patentaría ${ }^{22}$.

El recurso a una protección sistemática de los resultados de las investigaciones entraña necesariamente un retraso en su puesta a disposición de la comunidad científica. Para el hombre de ciencia publicar en una revista de investigación fundamental constituye un imperativo en el que se valida el resultado de la investigación, ya que de común, los trabajos son sometidos antes de su publicación al juicio crítico de colegas (referato). Sólo esta conducta puede observarse en el campo de la ciencia libre; la ciencia apropiada por vía de patentes escapa a los circuitos de verificación de la comunidad y de la prensa científica. La patente no incita a la cooperación ni al reparto de los avances, sino más bien a la disimulación de los resultados parciales y a la desinformación.

En resumidas cuentas la introducción masiva de la patente en el circuito de producción del conocimiento científico constituye una traba a su difusión y favorece los comportamientos de la desinformación ${ }^{23}$. La invasión de las inversiones y de las ganancias, figuras básicas del mundo de los negocios, pueden intensificar cualquier tendencia a guardar y a retener información ${ }^{24}$.

Con relación a la investigación fundamental Stiglitz entiende que existen algunas situaciones relevantes donde son altos los costos de la estrategia de una mayor apropiación. Este - agrega - es el caso particular de la investigación fundamental, porque los beneficios son extensos y difusos y los intereses de apropiarse de su rendimiento pueden retardar significativamente el sistema general de las innovaciones ${ }^{25}$.

En esta misma línea Dominique Foray señala que una privatización basada en patentes perjudica necesariamente otros modos de producción científica - publicaciones, conferencias, etc. - visto que el principio consiste en no divulgar el resultado antes de que sea protegido por patentes. A ello cabe agregar que la mayoría de tales patentes no pasa un examen serio conforme a los principios tradicionales del derecho de propiedad industrial ${ }^{26}$.

\section{El debilitamiento de la exclusión de los descubri- mientos}

A través de sucesivos avances jurisprudenciales se fue limitando la extensión de los descubrimientos excluidos de protección, en decisiones que contaron con el aval de la mayor parte de las oficinas de patentes y con argumentos harto discutibles, tal como surge de los hitos centrales que paso a exponer.

En el caso Antanamid del 28/07/77 el Tribunal de Apelaciones alemán en materia de patentes sentó la doctrina que las sustancias naturales no dejan de ser patentables. En principio - señaló - que si bien el solicitante había hecho sólo un descubrimiento que no se limitó a la aplicación del mismo, sino que suministró una indicación técnica del procedimiento de preparación de la sustancia considerada. El solicitante - adujo el tribunal - a través del hallazgo de antanamide en un tipo de setas había hecho sólo un descubrimiento; pero en tanto no se limitó sólo a la descripción del descubrimiento, sino que además suministró una indicación técnica del procedimiento de aislamiento de la sustancia considerada, podía acceder a una patente. La patente otorgada en este caso fue del producto (la sustancia natural), así como del procedimiento para su preparación.

Los principios de la sentencia Antanamid fueron confirmados y desarrollados en la sentencia Lactobacillus bavaricus en la que se destacó que los nuevos microorganismos, aun estando presentes en la naturaleza no habían sido descubiertos anteriormente y fue necesaria la intervención técnica del hombre para poder ser reconocidos y obtenidos de manera reproducible.

En el caso Chakrabarty la Corte Suprema norteamericana admitió por vez primera la patentabilidad de un ser vivo. En este caso entendió la mayoría de la Corte que el requirente produjo una nueva bacteria con características acentuadamente diferentes de cualquier otra encontrada en la naturaleza, poseyendo además un potencial de significativa utilidad. Este descubrimiento no es un trabajo de la naturale$z a$, sino del investigador, concluyendo que la bacteria es patentable en los términos del parágrafo 101 de la ley (como producto) ${ }^{27}$. 
En lugar de otorgar la patente para el procedimiento que permitió la modificación funcional de la bacteria, el pronunciamiento se extendió a patentar "un nuevo ser vivo" (el producto), lo cual es absurdo ya que la bacteria - aun con funciones alteradas no pierde su categoría originaria, pasando a ser una nueva especie. Para ratificar su posición sostuvo el tribunal que la ley de patentes no distingue entre objetos vivos o inanimados, sino entre productos de la naturaleza, vivos o no, e invenciones producidas por el hombre ${ }^{28}$. Hace falta mucha imaginación para concebir que la bacteria modificada sea una invención humana, en tanto no existió creación.

En el caso Bergy, el Tribunal del Circuito Federal de los Estados Unidos admitió la patentabilidad de un microorganismo hallado en la naturaleza aduciendo que la naturaleza y los usos comerciales de los cultivos biológicamente puros de microorganismos son análogos en la práctica a los productos químicos inanimados, usados como reactivos, como materia prima o como catalizadores en química industrial. No vemos ninguna distinción significativa desde el punto de vista legal - adujo el tribunal entre reactores químicos y organismos vivos per se utilizados como reactivos químicos ${ }^{29}$.

En el caso Myriad Genetics la Corte Suprema de los Estados Unidos admitió la patentabilidad del ADNc aduciendo que el técnico del laboratorio crea algo nuevo cuando se elabora ADNc ${ }^{30}$. El ADNc conserva los exones del ADN natural, pero es distinto del ADN del cual deriva. En conclusión, el ADNc no es un producto de la naturaleza y es patentable en virtud del artículo $101^{31}$.

La Corte fundamentó su resolución con los siguientes argumentos: los accionantes admitieron que el ADNc difiere del ADN natural en que las regiones no codificantes se han eliminado. Ellos argumentan, sin embargo, que no es patentable el ADNc porque la secuencia de nucleótidos está dictada por la naturaleza y no por el técnico de laboratorio. Puede que así sea - anota el tribunal - pero el técnico de laboratorio, sin dudas, crea algo nuevo cuando elabora ADNc. El ADNc conserva los exones del ADN natural, pero es distinto del $A D N$ del cual deriva. Como resultado, el $A D N c$ no es un "producto de la naturaleza" y es patentable en virtud del artículo 101.

Lo que expresa este razonamiento es que todo lo que tiene el sello humano, por más elemental que resulte la intervención del hombre, es patentable por cuanto se aleja del mundo natural, que es lo que circunscribe lo que está excluido de la protección patentaria. Con este criterio, el campo de lo patentable se ensancha a límites absurdos. Las decisiones anotadas tuvieron gran repercusión y la doctrina que en ellos se sentara fue acogida por la mayoría de las oficinas de patentes. Ellas nos ilustran acerca del estado de la cuestión pero dejan abiertos grandes interrogantes.

En efecto, una sustancia no pierde su naturaleza al ser aislada o preparada y en forma alguna puede admitirse que exista creación humana en tal actividad. Un ser vivo por más que sea sometido a cualquier alteración en su estructura para dotarlo de una nueva función, no deja de pertenecer a un mismo taxón biológico para pasar a integrar uno nuevo. Un microorganismo pertenece al mundo de la vida y un reactivo químico al mundo de lo inanimado, no pudiendo ser tratados en forma similar para fundar su patentabilidad. El ADNc que conserva la misma información genética que el ADN natural, al cual se le han separado las partes no codificantes mediante procedimientos ya conocidos, no importa una creación humana que meritúe ser patentado como producto.

Lo que se puede observar en estos casos es que estamos ante razonamientos difíciles de compartir, pero que en última instancia apuntan a justificar el resultado buscado: la patentabilidad. Cabe advertir como elemento común a todos ellos que la intervención humana, por poco determinante que fuere, constituye suficiente argumento para separar la línea divisoria entre descubrimiento e invención patentable.

Respecto a ello, observa Cassier que la operación que consiste en aislar, manipular y reproducir los efectos naturales es la definición misma de la actividad en los laboratorios científicos. La distinción entre el trabajo de descubrir una sustancia natural y la invención de un artefacto es así borrada. Todos los productos de laboratorio nacidos del trabajo de descubrirlos son potencialmente patentables, por poco que satisfagan los criterios clásicos de patentabilidad ${ }^{32}$. Repasando estas decisiones habría que coincidir con Robert Laughlin, premio Nobel de Física, en cuanto señalaba que la expansión de la ley de patentes suele cubrirse mediante el uso del lenguaje técnico ${ }^{33}$.

Originariamente las leyes de propiedad industrial tuvieron la intención de recompensar inventos reales y estimular la competencia, forzando a otros a que exploren nuevas rutas de investigación, en cuanto protegen de la competencia determinado objeto patentado. La posterior dilución de la integridad del sistema de patentes por medio injustificado de la competencia por la protección excesivamente abrazadora, no sólo detiene la competencia sino que tam- 
bién degrada los propósitos originales de la propiedad intelectual y la credibilidad del sistema patentario ${ }^{34}$.

La ruptura de la línea divisoria entre las leyes naturales y las "invenciones patentables"

A menudo se justifica el otorgamiento de patentes que no reivindican un esfuerzo creativo, sosteniendo - sobre todo en materia biológica - que la línea divisoria entre el invento y el descubrimiento se ha esfumado. Esta visión que pretende justificar el avance sostenido de la patentabilidad en terrenos ajenos a su ámbito legal encierra en los hechos una intencionalidad no disimulada de favorecer la apropiación indebida del conocimiento ${ }^{35}$.

M. C. Tallacchini, destacada investigadora en el campo jurídico de la biotecnología, entiende que el riesgo está en que la voluntad de acelerar el progreso biotecnológico pueda transformar a las patentes en una especie de fictio juris. En algunas patentes de material humano concedidas en los Estados Unidos puede encontrarse más la legitimación de mercado que el reconocimiento de un proceso innovador y creativo ${ }^{36}$.

No es cuestionable que un descubrimiento puede servir de base a múltiples invenciones, tal como lo hemos señalado. Lo que sí es cuestionable es que se utilice la patente para apropiarse de las bases fundamentales de esos descubrimientos, sin introducir un aporte técnico calificado.

En la práctica - se ha señalado - los tribunales inferiores y la United States Patent and Trademark Office (USTPO) han sido demasiado permisivos otorgando patentes que reivindican aplicaciones obvias de principios científicos recientemente descubiertos o que cubren de manera efectiva cualquier uso práctico del descubrimiento y que estas patentes tienen un impacto negativo en la investigación biomédica y en última instancia en la salud pública. Son numerosos los casos en los que se conceden patentes sobre pseudo invenciones que rozan las leyes naturales.

Un caso que ha sido ampliamente cubierto por la doctrina especializada es el que deriva del descubrimiento de una correlación entre ciertas mutaciones del gen BRCA1 y la susceptibilidad al cáncer de mama, que derivó en la concesión de varias patentes que en su conjunto abarcan cualquier procedimiento diagnóstico para detectarla, así como el propio gen, lo que dio lugar a varias decisiones judiciales en los Estados Unidos y en la Unión Europea, que limitan su alcance.

En el caso Metabolite Laboratories la patente otorgada se vincula al descubrimiento realizado sobre la correlación entre el nivel de homocisteína total en el cuerpo humano y la deficiencia de vitamina $B^{37}$. Basado en este descubrimiento se obtuvo una patente que reivindica cualquier método para detectar una deficiencia de vitamina $B$, que comprende las siguientes etapas: a) analizar en el fluido corporal de los pacientes la homocisteína; b) correlacionar una observación de la homocisteína total elevada con una deficiencia de vitamina B.

En un litigio promovido en torno a esta patente el Tribunal del Circuito Federal de los Estados Unidos declaró que la patente había sido vulnerada por los médicos que ordenaron pruebas de homocisteína a sus pacientes y utilizaron los resultados para el diagnóstico de deficiencia de vitamina B!!! ${ }^{38}$. Holman considera con toda razón que la patente concedida pareciera cruzar la línea de la materia no patentable al excluir cualquier uso práctico de un fenómeno natural ${ }^{39}$. En el caso de Classen Immunotherapies se hallaban implicadas cuatro patentes basadas en el descubrimiento de que la variación en las pautas de vacunación puede acarrear el riesgo de desarrollar trastornos autoinmunes crónicos ${ }^{40-43}$.

Las patentes concedidas, en líneas generales, reivindican métodos para delimitar trastornos de vacunación basados en la comparación de la incidencia de los efectos del sistema inmune entre dos o más grupos de sujetos inmunizados en diversos horarios. Un tribunal judicial al resolver un litigio sobre la validez de la patente concluyó que la correlación entre el calendario de vacunación y el riesgo de desarrollar un trastorno inmunológico es un fenómeno natural y que lo reivindicado importaba un intento indirecto de patentar la idea que existe una relación entre los programas de vacunación y los trastornos inmunes crónicos. Siguiendo el caso Metabolite, las patentes en cuestión pretendían abarcar de forma efectiva cualquier explotación práctica de una correlación biológica ahora descubierta, pero preexistente en la naturaleza.

En el caso Ariad Pharmaceuticals la patente se basó en un descubrimiento hecho por un investigador del factor de transcripción NF-kB (factor nuclear Kapa B) del papel central que desempeña la senda NF-kB en la expresión génica en una variedad de contextos ${ }^{44}$. Una empresa competidora del titular planteó a la justicia la invalidez de la patente por reivindicar de una forma inadmisible un principio de la naturaleza. Al igual que los casos anteriores la patente de Ariad pareciera cubrir ampliamente cualquier aplicación práctica del descubrimiento omnipresente en la ruta NF-kB, reivindicando el uso de medicamentos que afectan inadvertidamente esa vía, pero que se desarrollan sin la intención específica de afectar a NF-kB. 
Mostrando estas decisiones judiciales y administrativas Holman señala que estas patentes pueden servir como obstáculo y falta de incentivos para las actividades de seguimiento de la investigación y desarrollo comercial para transformar los descubrimientos fundamentales en tecnologías potencialmente dirigidas a salvar vidas ${ }^{39}$.

Hace tres lustros que J. Barton alertaba sobre el riesgo de que la concesión de patentes básicas muy amplias sobre procesos de investigación fundamental frene y complique la investigación subsiguiente ${ }^{9}$.

Lo que aquí debe reprocharse es el intento de obtener patentes en base a la simple aplicación de un principio o de una ley natural sin que exista un verdadero y real aporte inventivo. Esto se da con demasiada frecuencia, creando problemas a la investigación que en lugar de ver abiertos los caminos a recorrer se encuentra con impedimentos legales que desaniman a utilizar las vías abiertas.

La concesión de patentes sobre invenciones que rozan las leyes naturales constituye un claro abuso de derecho y muestran la desaprensión o en algunos casos la complicidad de las oficinas de patentes que al olvidar criterios elementales de examen, se convierten en los hechos en verdaderas agencias dispensadoras de privilegios indebidos.

\section{Consideraciones finales}

La relación entre patentes de invención e investigación científica no es en principio conflictiva. Si se observan los principios centrales receptados por los sistemas jurídicos nacionales y por el Acuerdo de los Acordo sobre os aspectos dos Direitos de Propriedade Intelectual relacionados com o Comércio (ADPIC) - existencia de una invención patentable que respete los requisitos objetivos de patentabilidad (novedad, mérito inventivo, aplicación o utilidad industrial) - pueden coexistir sin interferencias ni perjuicios.

El tema adquiere otra connotación cuando - tal como ocurre con demasiada frecuencia-se ad- mite la patentabilidad de descubrimientos, se conceden patentes en los primeros pasos del proceso de investigación o respecto de leyes naturales. Aquí el perjuicio para la actividad científica es evidente.

Hoy podemos advertir un panorama desalentador en cuanto al número y calidad de las patentes otorgadas. Tanto las oficinas de patentes como los tribunales judiciales observan una permisibilidad absurda, que no mide las consecuencias sociales de sus decisiones. Las patentes mal concedidas aparte de afectar la competencia - tema ajeno al que nos ocupa - entorpecen la investigación científica.

Se han elaborado criterios jurisprudenciales que carecen del necesario aval normativo pero que una vez lanzados se convierten en construcciones dogmáticas que se reiteran en todas las latitudes. En este cuadro - en cierta forma perverso - podemos observar a diario que una parte considerable de los avances de investigación básica se encuentra blindada por patentes que crean inexplicables barreras a la libre circulación del conocimiento. A las crecientes presiones del sector industrial se suman en no pocos casos las que ejercen universidades y agencias estatales, que olvidan la preeminencia del interés público. La investigación científica necesita de un clima de libertad y de seguridad en un momento estelar de su desarrollo que en muchos casos hace nacer fundadas esperanzas de futuro.

No desconocemos los aspectos positivos que puede generar la relación de la investigación científica con la industria, pero para que ello se de no es necesario ni conveniente que se desconozcan los fundamentos de los derechos de la propiedad industrial haciendo de las patentes un título que sólo sirve para anular la competencia, ni que se alteren los principios que inspiraron e inspiran la investigación científica. Toda traba injustificada al desarrollo de ésta, importa al mismo tiempo un ataque a la sociedad en su conjunto. Se torna necesario tomar debida nota de los problemas que genera la apertura irrestricta de los derechos de exclusiva y que se privilegie la investigación científica como un bien público de preponderante interés social.

\section{Referências}

1. Unión Europea. Directiva 98/44/CE del Parlamento Europeo y del Consejo, de 6 de julio de 1998, relativa a la protección jurídica de las invenciones biotecnológicas. [Internet]. 1998 [atualizada 4 jul 2011; acesso 5 ago 2014]. Disponível: http://europa.eu/legislation_summaries/internal_ market/single_market_for_goods/pharmaceutical_and_cosmetic_products/I26026_es.htm

2. Pestre D. Ciencia, dinero y política. Buenos Aires: Nueva Visión; 2005. p. 115.

3. Correa CM. Producción y comercialización de conocimientos científicos y tecnológicos: los retos de la propiedad intelectual en el Siglo XXI. Lima: INDECOPI; 1996. p. 53. 
4. Pestre D. Op. cit. p. 103.

5. Pestre D. Op. cit. p. 98.

6. Lionel BL, Sherman B, Barbosa DB, Grau-Kuntz K, Basheer S, Purohit $\mathrm{S}$ et al. Exclusiones a la patentabilidad y excepciones y limitaciones a los derechos de los titulares de patentes. In: Organización Mundial de la Propiedad Intelectual. Comité Permanente sobre el Derecho de Patentes. Decimoquinta Seción, Ginebra, 11-15 octubre 2010. Estudio de expertos sobre exclusiones de la materia Patentable y excepciones y limitaciones a los derechos conferidos por las patentes: SCP/15/3. [Internet]. Ginebra: OMPI; 2010 [acesso nov 2014]. Anexo I, p.2. Disponível: http://www.wipo.int/edocs/mdocs/scp/es/scp_15/scp_15_3-annex1.pdf

7. Dal Paz M, Barbosa DB. Incertezas e riscos no patentamiento de biotecnología. In: Iacomini V, coordenador. Propriedade intelectual e biotecnologia. Curitiba: Jurúa; 2008. p. 95.

8. Kahn A. Proprieté intellectuelle et recherche sur le genome: reflexions sur un coloque. In: Institut de France-Academie des Sciences. La proprieté intellectuelle dans le domain du vivant. Paris: TECDOC; 1995. p.261.

9. Barton J. Derechos de propiedad intelectual: hacia una reforma del sistema de patentes. Revista Jurisprudencia Argentina. 29 set 2000:1.

10. Office European des Brevets. Chambres de Recours. Decision Recours no T301/87 del 16/02/87. Logo European Patent Office Recherche dans le site. Limiter la recherche à la présente rubrique Recherche avancée. Recherche de brevets. [Internet]. 16 fev 1989 [acesso nov 2014]. Disponível: http://www.epo.org/law-practice/case-law-appeals/recent/t870301fp1.html\#q=

11. Franceschi M. Droit et marchandisation de la connaissance sur les gens humains. Paris: CNRS; 2004. p. 176.

12. Franceschi M. Op. cit. p. 177.

13. Correa C, Bergel SD. Régimen legal de las patentes de invención. Buenos Aires: La Ley; 2013. t. II, p. 107.

14. Marshall E. Bermuda rule: communitary spirit with teeths. Science. 2001;291(5507):192.

15. Heller MER, Eisenberg RS. Can patents deter innovation? The anticommons in biomedical research. Science. 1998;280(5364):698.

16. Dal Paz M, Barbosa Db. Op. cit. p. 93.

17. Ost V. Les brevets portant sur les inventions biotechnologiques. In: Remiche B. Brevets, innovation et interèt general. Bruxelles: Larcier; 2007. p. 131.

18. Eisenberg R. Structure and function in gene patenting. Nat Genet. 1997;15:125.

19. Nuffield Council on Bioethics. The ethics of patentability of DNA. London: NCB; 2002. p. 65.

20. Correa C, Bergel SD, Kors J. Op. cit. p. 195.

21. Pestre D. Op. cit. p. 103.

22. Franceschi M. Op. cit. p. 166.

23. Franceschi M. Op. cit. p. 169.

24. Kornberg A. La hélice de oro. Bernal: Edit. Universidad de Quilmas; 2002. p. 275.

25. Stiglitz J. El conocimiento como bien público mundial. In: Kaul I, Grunberg I, Stern MA, editors. Bienes públicos mundiales: la cooperación internacional en el siglo XXI. México: Oxford University Press; 2001. p. 328-45.

26. Dias Varella. Propriedade intelectual e desenvolvimento. São Paulo: Lex; 2005. p. 75.

27. Bergel SD. La patentabilidad de seres vivos (a 30 años de Chakrabarty). La Ley. 25 mar 2010B:1269.

28. Chakrabarty A, inventors; Gen Electric, assignee. Microorganisms having multiple compatible degradative energy-generating plasmids and preparation thereof. United States patent US 3813316 A. [Internet]. 28 may 1974[acesso nov 2014]. Disponível: http://www.google.com/ patents/US3813316

29. United States Patent Quarterly. 1979;352:201.

30. Franceschi M. Op. cit. p. 13.

31. Bergel SD. Enfoque ético-jurídico de la sentencia de la Corte Suprema de los Estados Unidos sobre patentabilidad de genes humanos. Rev bioét (Impr.). 2014;22(1):18.

32. Cassier $M$. La tendance à la privatisation de la recherche génétique et quelques mesures de régulation et de coordination. In: Laperche B. Proprieté intelectuelle et innovation. Paris: L'harmattan; 2000. p. 127.

33. Laughlin R. Crímenes de la razón. Buenos Aires: Ed. Katz; 2010. p. 60.

34. Iacomini V. Os direitos de propriedade intelectual e a biotecnologia. In: lacomini V, coordenador. Propriedade intelectual e biotecnologia. Curitiba: Jurúa; 2008. p. 26.

35. Schmid-SZalewski J. La notion d'invention face aux developments technologiques. In: SchmidSZalewski J. La notion d'invention face aux developments technologiques. In: Roche MAF, Abello A. Droit et Économie de la propriété intellectuelle, Paris: L.G.D.J. 2005. p. 253.

36. Tallacchini M C. Umbrales de bioartificialidad: las oscilaciones de la patentabilidad genética. Rev Derecho Genoma Hum. 2003;(18):115.

37. Allen RH, Stabler SP, Lindenbaum J, inventors; University Patents, assignee. Assay for sulfhydryl amino acids and methods for detecting and distinguishing cobalamin and folic acid deficency . United States patent US 4940658. [Internet]. 10 jul 1990 [acesso nov 2014]. Disponível: https:// www.google.com/patents/US4940658

38. United States Court of Appeals for the Federal Circuit. Metabolite Laboratories Inc. and Competitive Technologies Inc. v. Laboratory Corporation of America Holdings, n. 370 F3d 1354 (Fed Cir 2004). 
39. Holman CM. Patent border wars: defining the boundary between scientific discoveries and patentable inventions. Trends Biotechnol. 2007;25(12):539-43.

40. Tsutsui T, Kojima M, Suzuki M, Sakamoto K, Nishijima M, inventors; Chisso Corporation, assignee. Split type conjugate fiber, method for producing the same and fiber formed article using the same. United States patent US 6.410.139. [Internet]. 14 sep 2000 [acesso nov 2014]. Disponível: http://patft.uspto.gov/netahtml/PTO/search-bool.html

1. Classen JB, inventors; Classen Immunotherapies, Inc., assignee. Method and composition for an early vaccine to protect against both common infectious diseases and chronic immune mediated disorders or their sequelae. United States patent US 6638739. [Internet]. 18 abr 2002 [acesso nov 2014]. Disponível: http://patft.uspto.gov/netahtml/PTO/search-bool.html

42. Classen JB, inventors; Classen Immunotherapies, Inc., assignee. Method and composition for an early vaccine to protect against both common infectious diseases and chronic immune mediated disorders or their sequelae. United States patent US 5.728.385. [Internet]. 12 aug 1993 [acesso nov 2014]. Disponível: http://patft.uspto.gov/netahtml/PTO/search-bool.html

43. Classen JB, inventors; Classen Immunotherapies, Inc., assignee. Method and composition for an early vaccine to protect against both common infectious diseases and chronic immune mediated disorders or their sequelae. United States patent US 5.723.283. [Internet]. 31 may 1995 [acesso nov 2014]. Disponível: http://patft.uspto.gov/netahtml/PTO/search-bool.html

44. Baltimore D, Sen R, Sharp PA, Singh H, Staudt L, LeBowitz et all, inventors; President and Fellows of Harvard College, Massachusetts Institue of Techonology, Whitehead Institute for Biomedical Research, assignee. Nuclear factors associated with transcriptional regulation. United States patent US 6410516. [Internet]. 15 jun 2002 [acesso nov 2014]. Disponível: https://www.google. com/patents/US6410516

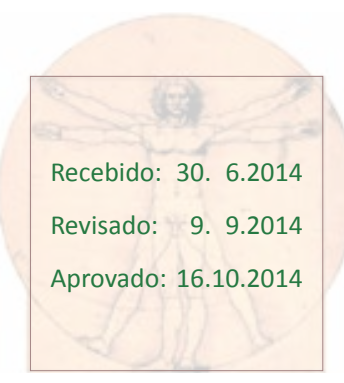

